Первый Московский государственный медицинский университет имени И.М. Сеченова (Сеченовский Университет), Москва, Россия

Мелатонин является уникальным гормоном и хронобиотиком, синхронизирующим эндогенные циркадианные ритмы организма, его физиологию и поведение с окружающей средой. Современный урбанизированный уклад общества и процессы промышленного производства напрямую зависят от наличия искусственного освещения в ночное время и включают распространенное использование электронных устройств, экраны которых излучают свет синего спектра. Наличие освещения в ночные часы задерживает начало секреции мелатонина в организме и снижает его пик, вызывая хроническую гипомелатонинемию. Гипомелатонинемия совместно с вызываемыми ей депривацией сна, нарушением пищевого поведения, углеводного и жирового обмена является одной из причин «неинфекционной эпидемии XXI в.» - экзогенно-конституционального ожирения. Учитывая это, применение препаратов мелатонина для коррекции гипомелатонинемии у лиц с экзогенно-конституциональным ожирением может иметь определенные перспективы. Неоднократно была показана эффективность подобных препаратов в испытаниях in vitro и на животных моделях, есть данные о влиянии препаратов мелатонина на снижение массы тела и резистентности к инсулину у человека. Для подтверждения гипотезы о перспективах их применения требуются дальнейшие проспективные контролируемые рандомизированные исследования в этой области.

КЛЮЧЕВЫЕ СЛОВА: мелатонин; ожирение; инсулинорезистентность; пищевое поведение; сон; циркадианные ритмы; сменный график работы.

\title{
THE IMPORTANCE OF MELATONIN IN THE REGULATION OF METABOLISM, EATING BEHAVIOR, SLEEP, AND THE PROSPECTS FOR THE USE OF MELATONIN DRUGS FOR OBESITY TREATMENT
}

\author{
(c) Evdokiia S. Tsvetkova*, Tatiana I. Romantsova, Mickhail G. Poluektov, Guzel E. Runova, Irina V. Glinkina, Valentin V. Fadeev
}

I.M. Sechenov First Moscow State Medical University (Sechenov University), Moscow, Russia

Melatonin is a special hormone that act as an internal synchronizer of circadian rhythms, the organism physiology and behavior to the environmental day and night and seasons of the year. The present urban society and the industrial production processes as organized should be considered, as both depend on the presence of indoor lights during the night and include the profuse use of electronic devices whose screens are rich in blue wavelength light. Light during the night delays the beginning of the secretory episode of melatonin and blunts its peak, causing chronic hypomelatoninemia. Hypomelatonemia, that causes deprivation of sleep and eating behavior disorders, along with low physical activity, can be the reason of the obesity, «non-infectious epidemic of the 21 st century». According to this, the use of melatonin drugs for obesity treatment can be effective. Further prospective, controlled, randomized trials in this area are required to confirm this hypothesis.

KEYWORDS: melatonin; obesity; insulin resistance; eating behavior; sleep; circadian rhythms; shift work schedule.

\section{ТЕРМИНОЛОГИЧЕСКИЙ СЛОВАРЬ}

1. Биологические часы - внутренние генетически запрограммированные ритмические механизмы, служащие для упорядочивания во времени биологических функций и поведения.

2. Е-бокс (от англ. enhancer box, E-box) - ДНК-последовательность, найденная в некоторых промоторных областях у эукариот, которая регулирует экспрессию генов.

3. Кривая фазового отклика (КФО) мелатонина показывает величину отклика, полученную в результате воздействия мелатонина на органы-мишени и находящуюся в прямой зависимости от момента прекращения действия мелатонина в течение эндогенного циркадианного периода.
4. Осциллятор - система, совершающая колебания; показатели системы периодически повторяются во времени.

5. Открытие ворот сна (открытие ночных ворот сна) резкое увеличение сонливости, которое возникает в поздние вечерние часы и отмечает начало периода, характеризуемого неизменно высокой сонливостью.

6. Таймер (zeitgeber) - конфигурация стимула, предоставляющая осциллятору информацию относительно временных циклов (например, солнечный свет).

7. Хронотип - предпочтение человеком утренней (жаворонок) или вечерней (сова) деятельности. Особенности хронотипа обычно совпадают с преобладанием в соответствующее время суток объективных показателей, характеризующих активность физиологических функций.

*Автор, ответственный за переписку / Corresponding author. 
8. Циркадианные гены - гены, обеспечивающие регуляцию циркадианных часов и поддерживающие эндогенную продолжительность циркадианного ритма.

9. Циркадианные ритмы - ритмы, имеющие период около 24 ч. Обычно к ним причисляют ритмы с периодами от 20 до 28 ч.

10. Циркадианные часы (синоним: клеточные часы) биохимический клеточный осциллятор, который имеет фазовые колебания и периодически синхронизируется с таймерами (например, солнечным светом).

11. Эндогенная продолжительность циркадианного ритма - продолжительность фазового колебания осциллятора, поддерживаемая циркадианными часами.

\section{ПОИСК И КРИТЕРИИ ОТБОРА ЛИТЕРАТУРНЫХ ИСТОчнИков}

При подготовке обзора были использованы следующие полнотекстовые и библиографическо-реферативные базы данных: Национальной медицинской библиотеки США (PubMed, Medline); научной электронной библиотеки eLIBRARY.RU; научной электронной библиотеки КиберЛенинка (cyberleninka.ru). Поиск источников первичной информации осуществлялся на глубину 20 лет (2001-2021 гг.) по следующим ключевым словам (в англоязычных базах данных - с соответствующим переводом): мелатонин; ожирение; нарушение циркадианных ритмов; гипомелатонинемия; метаболический синдром; ожирение; ожирение и нарушение циркадианных ритмов; ожирение и мелатонин; ожирение и гипомелатонинемия; патогенез ожирения; патогенез метаболического синдрома; эпидемиология нарушения циркадианных ритмов и метаболического синдрома. Сайты издательств Springer и Elsevier использовались для доступа к полному тексту англоязычных статей.

\section{ВВЕДЕНИЕ}

Мелатонин, называемый также «гормоном сна», является индольным производным триптофана. Мелатонин обладает особыми антиоксидантными свойствами, предполагают, что эта функция мелатонина является основной и филогенетически наиболее древней. Синтез мелатонина был описан у большинства живых организмов. У позвоночных, включая человека, секреция мелатонина происходит как на периферии, так и в центральной нервной системе (ЦНС), в специальной эндокринной железе - эпифизе.

Секреция эпифизарного мелатонина находится под контролем супрахиазмальных ядер (СХЯ) продолговатого мозга. Первичным таймером, который адаптирует СХЯ к 24-часовому циклу, является дневной свет, действующий опосредованно через фоторецепторы сетчатки и ретиногипоталамический тракт. В ответ на фотораздражитель происходит высвобождение норадреналина из синапсов нервных волокон, идущих от СХЯ к эпифизу, и блокируется превращение триптофана в мелатонин. Выработка мелатонина происходит исключительно в темное время суток.

При искусственном освещении в ночное время синтез мелатонина тормозится. У человека подобный эффект фотоингибирования реализуется в первую очередь при освещении синим светом (460-480 нм) интенсивностью от 60 до 130 люкс, источником которого в квартире являются люминесцентные лампы и экраны электронных приборов [1-3]. Эти два фактора (синхронизация с циклом свет/темнота и фотоингибирование) обусловливают роль мелатонина как хрономолекулы, которая синхронизирует эндогенный циркадианный ритм организма с внешней средой.

Наряду с эпифизарным (пинеальным) существует экстрапинеальный мелатонин. Присутствие этого гормона и ферментных механизмов для его синтеза было обнаружено во многих органах и тканях [4-6]. В настоящее время считается, что мелатонин синтезируется в митохондриях любой клетки животного организма [7]. Так, в желудочно-кишечном тракте этого гормона в 400 раз или более больше, чем в шишковидной железе. Мелатонин синтезируется энтерохромаффинными клетками (апудоцитами) и является эндокринной, паракринной или аутокринной сигнальной молекулой. Апудоциты широко представлены в органах желудочно-кишечного тракта (ЖКТ), в том числе в поджелудочной железе и гепатобилиарной системе. Синтез и реализация функций такого мелатонина полностью аналогичны пинеальному. Часть мелатонина, синтезированного энтероэндокринными клетками ЖКТ, попадает в портальный кровоток, откуда он поглощается печенью. Затем мелатонин метаболизируется и выводится с желчью в тонкий кишечник и, наконец, возвращается в печень через энтеропеченочную циркуляцию [8].

Как показано далее, мелатонин не только реализует важные для организма функции антиоксиданта и хронобиотика, но и оказывает влияние на углеводный обмен, секрецию инсулина, лептина, адипонектина, пролиферацию адипоцитов и пищевое поведение. Особенности эффектов мелатонина на организм позволяют рассматривать нарушения его синтеза как одно из звеньев патогенеза экзогенно-конституционального ожирения и обосновать возможность применения препаратов мелатонина при этом заболевании [7].

\section{МЕХАНИЗМЫ ДЕЙСТВИЯ МЕЛАТОНИНА}

Амфифильность мелатонина позволяет ему проникать через клеточные и ядерные мембраны и напрямую взаимодействовать с внутриклеточными структурами. Антиоксидантные эффекты мелатонина заключаются в ингибировании образования гидроксильных радикалов, защите липидов, белков и ДНК от оксидативного стресса, предотвращении мутаций ДНК и клеточного апоптоза [9]. Мелатонин действует несколькими способами, чтобы ограничить окислительный стресс: как без участия рецепторов к мелатонину, просто нейтрализуя свободный радикал при помощи одного из своих электронов, так и рецептор-опосредованно [10]. Эти рецептор-опосредованные действия мелатонина являются косвенными и, вероятно, включают стимуляцию антиоксидантных ферментов - глутатионпероксидазы (GPX), супероксиддисмутазы (SOD-1,-2), сиртуина 3 (SIRT3) и т.д. [11]. В случае если мелатонин действует через рецепторы для осуществления своего антиоксидантного действия, он может достичь этого эффекта при гораздо более низких концентрациях, чем те, которые требуются, 
когда он действует как прямой поглотитель свободных радикалов. Это связано с тем, что пути передачи сигнала, связанные с рецепторами, служат для усиления ответа. Предполагают также, что мелатонин может напрямую влиять на экспрессию часовых генов [12].

Рецептор-опосредованное действие мелатонин оказывает на мембранные высокочувствительные G-белковые рецепторы MTNR1A и MTRN1B, также известные как MT1 и МТ2 [13]. Они находятся в ряде областей ЦНС, включая СХЯ, медиально-базальный гипоталамус, таламус, височную, теменную и лобные доли, гиппокамп, преоптическую область, базальные ганглии, area postrema, сетчатку, мозжечок и pars tuberalis [14]. Также MT1- и МT2-рецепторы содержатся в жировой ткани, островках поджелудочной железы, печени и др. [15, 16]. Третий тип мелатонинсвязывающего белка, расположенного на клеточной мембране млекопитающих, названный сначала ML2рецептором, - МТ3 представлен хинонредуктазой II и называется сайтом связывания с рецептором [17]. Этот белок называть рецептором некорректно, т.к. он имеет область связывания с различными лигандами, но не вызывает инициации сигнальных путей. МТ3 катализирует восстановление хинонов до хинолов, что имеет важное значение для окислительного стресса, таким образом, он участвует в реализации мелатонин-индуцированной цитотоксичности и апоптоза опухолевых клеток [18, 19]. Также мелатонин действует на ядерные рецепторы, принадлежащие к суперсемейству рецепторов ретиноевой кислоты RORa (NR1F1) и RORß (NR1F2), и ретиноидный рецептор $Z$, тем самым участвуя в настройке циркадианных часов [20].

\section{ЭФФЕКТЫ МЕЛАТОНИНА}

Особенностью мелатонина является широкий спектр его немедленных, отсроченных и хронобиотических эффектов.

Фактически биологическая роль мелатонина заключается в том, чтобы инициировать в ночную фазу приспособительные механизмы для отдыха и с помощью отсроченных эффектов подготовить физиологию и поведение для адаптации к активности в дневную фазу.

Немедленные эффекты мелатонина являются следствием его классического гормонального действия и проявляются в течение ночи. В это время происходит секреция мелатонина, он присутствует в крови и спинномозговой жидкости. У человека, как вида с дневной активностью, эти эффекты мелатонина включают индукцию сна, снижение артериального давления и температуры, снижение секреции кортизола, повышение резистентности к инсулину и снижение толерантности к глюкозе.

Отсроченные эффекты мелатонина запускаются ночью, но реализуются только в течение следующего дня после прекращения гормонального сигнала [21].

Отсроченными эффектами мелатонина у человека являются индукция дневной чувствительности к инсулину, повышение чувствительности поджелудочной железы к глюкозе, индуцированная инкретинами секреция инсулина, увеличение артериального давления и потребления энергии в дневные часы.

Отсроченные эффекты мелатонина разделяют на проксимальные и дистальные.
Проксимальные отсроченные эффекты мелатонина проявляются сразу после прекращения его действия на рецепторы. При адекватной синхронизации организма с циклом свет/темнота эти эффекты проявляются в начале следующего дня и могут длиться несколько часов. Одним из проксимальных эффектов мелатонина является регуляция экспрессии циркадианных генов петли обратной связи транскрипции-трансляции (The TranscriptionTranslation Feedback Loop) в клетках ЦНС и $\beta$-клетках поджелудочной железы.

У человека проксимальный отсроченный эффект мелатонина лучше всего изучен на $\beta$-клетках поджелудочной железы: он влияет на жизненный цикл, функцию и циркадианный ритм $\beta$-клеток, сенсибилизирует их к глюкагоноподобному пептиду 1 (ГПП-1), что приводит к увеличению секреции инсулина $[22,23]$. Есть данные о том, что длительное воздействие мелатонина в течение ночи может предотвращать быструю десенсибилизацию цАМФ (циклический аденозинмонофосфат)-зависимого рецептора ГПП-1, тем самым увеличивая аффинность рецепторов к ГПП-1 на следующее утро [24]. Кроме того, было показано, что в изолированных островках Лангерганса при гипергликемии мелатонин значительно снижает окислительный стресс и усиливает глюкозозависимую секрецию инсулина. Подобный эффект мелатонина был продемонстрирован на животных моделях и на островках, полученных посмертно от пациентов с сахарным диабетом 2 типа [22].

Дистальные отсроченные эффекты мелатонина проявляются в любое время в течение следующего дня уже в отсутствие циркулирующего мелатонина. Они опосредуются регуляцией экспрессии циркадианных генов, трансляцией и деградацией белков. Эти эффекты нивелируются новым эпизодом секреции мелатонина в течение следующей ночи.

Мелатонин модулирует период, амплитуду и фазу суточной экспрессии циркадианных генов, является хронобиотиком для центрального пейсмейкера (СХЯ) и периферических осцилляторов ( $\beta$-клеток, печени, скелетных мышц и жировой ткани) [25-27]. Это означает, что последовательная и повторяющаяся ежедневная секреция мелатонина в ночное время и контраст между его высокой ночной концентрацией и отсутствием или очень низкой концентрацией в дневные часы помогают правильно настроить циркадианные часы так, чтобы физиология и поведение (в том числе пищевое) были синхронизированы с циклом день/ночь окружающей среды. Мелатонин контролирует часовые гены и колебания циркадианного ритма в клетках Лейдига, ооцитах, клетках коры надпочечников, сетчатке, фибробластах кожи, кардиомиоцитах и гладкомышечных клетках миометрия. Даже микробиота и паразитические организмы могут синхронизироваться с помощью мелатонина хозяина, что было показано для малярийного плазмодия и комменсальной бактерии желудочно-кишечного тракта Enterobacter aerogenes.

Отсутствие или уменьшение амплитуды колебаний мелатонина может привести к аритмичности часовых генов. В подобных случаях терапия мелатонином нормализует экспрессию часовых генов и циркадианные ритмы.

Благодаря своим свойствам и механизмам действия мелатонин регулирует клеточный метаболизм практически в каждом типе клеток. 


\section{РОЛЬ МЕЛАТОНИНА В РЕГУЛЯЦИИ МЕТАБОЛИЗМА, ПИЩЕВОГО ПОВЕДЕНИЯ И СНА}

Мелатонин играет важную роль в регуляции энергетического обмена, в том числе массы тела, чувствительности к инсулину и толерантности к глюкозе. Эффекты мелатонина реализуются на этапах потребления энергии (питание), перераспределения энергетических запасов и расхода энергии.

Мелатонин синхронизирует пищевое поведение человека с метаболическими процессами, обеспечивающими хранение энергии $[21,27,28]$.

На животных моделях также продемонстрирована роль материнского мелатонина в качестве эпигенетического фактора, регулирующего внутриутробное и неонатальное программирование энергетического обмена [29].

\section{МЕЛАТОНИН И УГЛЕВОДНЫЙ ОБМЕН}

Фаза бодрствования (дневная фаза для человека) связана с повышением секреции инсулина, чувствительности клеток к инсулину и толерантности к глюкозе и инсулинзависимого поглощения глюкозы клетками. В эту фазу происходит гликолиз в печени и мышцах, синтез гликогена, блокируется глюконеогенез в печени.

Для фазы сна (ночной фазы для человека) характерны отсутствие поступления пищи и использование накопленной днем энергии для поддержания жизни. Эта фаза суточного цикла характеризуется снижением уровня глюкозы и инкретинов, резистентностью к инсулину, усилением глюконеогенеза и гликогенолиза в печени.

Мелатонин регулирует секрецию инсулина и действие инсулина. У людей (дневных млекопитающих) выброс мелатонина вызывает снижение толерантности к глюкозе вечером, ночью и ранним утром [30].

На поверхности мембран $\beta$ - и а-клеток поджелудочной железы были идентифицированы специфические мелатониновые рецепторы MT1 и MT2. При этом в $\beta$-клетках в большей степени представлены рецепторы MT2, а в а-клетках - МТ1. В эксперименте с изолированными панкреатическими островками человека добавление мелатонина стимулирует МТ1-рецепторы а-клеток, что повышает секрецию глюкагона и одновременно за счет включения цГМФ (циклический гуанозинмонофосфат)-сигнального пути через рецепторы МT2 тормозит выработку инсулина $\beta$-клетками. Немедленными эффектами секреции мелатонина в ночное время являются выживание $\beta$-клеток, сохранение их массы и функции [22]. Одновременно за счет своих отсроченных эффектов мелатонин подготавливает увеличение чувствительности к инсулину и сенсибилизацию рецепторов к ГПП-1 в дневное время.

Пинеалэктомия у крыс вызывает нарушение толерантности к глюкозе и увеличение резистентности к инсулину, нарушение циркадианного цикла энергетического обмена, увеличение потребления пищи и снижение расхода энергии, приводящее к увеличению массы тела [31]. В отсутствие мелатонина происходит уменьшение общего количества рецепторов ГЛЮТ-4 во всех чувствительных к инсулину тканях (жировой ткани, скелетных и сердечной мышцах) и нарушение передачи инсулинового сигнала [32].
Отмечают наличие связи между поломками мелатониновых рецепторов и развитием нарушений углеводного обмена: у мышей, лишенных МТ1-рецепторов, резко нарушается метаболизм глюкозы и возрастает резистентность к инсулину [33]. Это позволяет рассматривать нарушения в мелатонинергической системе как серьезный фактор риска развития сахарного диабета 2 типа [34].

Предполагают, что отношения между мелатонином и инсулином имеют реципрокную организацию: не только мелатонин модулирует эндокринную функцию поджелудочной железы, но и уровень плазменного инсулина влияет на секрецию мелатонина эпифизом.

У человека важность регулярной секреции мелатонина, определяющей высокую чувствительность к инсулину в дневные часы, продемонстрирована в нескольких клинических и эпидемиологических исследованиях, показывающих достоверную связь между сниженной продукцией мелатонина, инсулинорезистентностью и высоким риском развития диабета 2 типа [35, 36]. Фотоингибирование синтеза мелатонина при увеличении ночного освещения индуцирует дневную инсулинорезистентность и уменьшает утреннее ГПП-1-индуцированное высвобождение инсулина [36]. Кроме того, несколько работ показывают связь между дисфункцией мелатонинового рецептора, возникающей в результате однонуклеотидного полиморфизма, и сахарным диабетом 2 типа, гестационным диабетом и инсулинорезистентностью при синдроме поликистозных яичников [37].

\section{МЕЛАТОНИН И ЖИРОВАЯ ТКАНЬ}

Первые доказательства прямого действия мелатонина на адипоциты были представлены Lima и соавт. в 1994 г. Они продемонстрировали повышение чувствительности изолированных адипоцитов к инсулину при их обработке мелатонином. Экспрессия рецепторов МT1 и MT2 в адипоцитах была выявлена на животных моделях, а затем у человека - в клетках бурой и белой жировой ткани [16].

Влияние мелатонина на белую жировую ткань происходит не только посредством стимуляции рецепторов, но и через симпатическую нервную систему. Существуют убедительные доказательства симпатической иннервации белой жировой ткани, причем центральным регулятором являются СХЯ, имеющие рецепторы к мелатонину. На животных моделях продемонстрировано, что введение мелатонина в период короткого светового дня приводит к большей экспрессии МT1 в СХЯ, увеличению липолиза, снижению потребления пищи и уменьшению сезонного ожирения [38].

Периодическое воздействие мелатонина на адипоциты синхронизирует их метаболические и гормональные функции с циркадианным ритмом день/ночь. У крыс при пинеалэктомии изменяется картина экспрессии часовых генов в жировой ткани, развиваются ожирение и метаболический синдром [39]. Интересно, что диета с высоким содержанием жиров вызывает значительные изменения в экспрессии часовых генов передней доли гипофиза крыс и снижение амплитуды ночного уровня мелатонина.

Jiménez-Aranda и соавт. (2013) продемонстрировали, что у крыс мелатонин (10 мг/кг/день в питьевой воде 
в течение 6 нед) вызвал трансформацию паховой белой жировой ткани в бурую и увеличивал количество термогенных белков в бежевом жире [40]. В исследовании Halpern и соавт. (2019) была показана способность экзогенного мелатонина увеличивать количество бурой жировой ткани у людей с нехваткой эндогенного мелатонина (перенесших пинеалэктомию или радионуклидную терапию области эпифиза) [41].

Такое действие мелатонина может быть опосредовано сразу несколькими механизмами: активацией симпатической иннервации жировой ткани, прямой стимуляцией дифференциации преадипоцитов и трансдифференцировкой белых адипоцитов в бурые [42]. Таким образом, способность мелатонина к трансформации белой жировой ткани в бурую может способствовать его метаболическим преимуществам и контролю массы тела.

Подтвержденные связи между жировой тканью и мелатонином делают актуальным вопрос о том, влияет ли мелатонин на синтез и секрецию двух основных адипокинов, участвующих в энергетическом обмене, - лептина и адипонектина.

Было показано, что лептин, мелатонин и инсулин активируют одни и те же внутриклеточные сигнальные пути, а именно РI3K и STAT-3. Предполагают, что из-за этого мелатонин может модулировать действие инсулина на адипоциты и влиять на чувствительность рецепторов гипоталамуса к лептину и инсулину, передавать информацию о жировом запасе в гипоталамус, способствуя коррекции дисбаланса энергии в организме [43].

В исследованиях у женщин с метаболическим синдромом наблюдалось снижение суточной амплитуды секреции мелатонина, а у мужчин с ожирением отмечались измененные ритмы секреции мелатонина [44, 45]. Циркадианная амплитуда мелатонина обратно пропорционально коррелировала с уровнем лептина в плазме, а также с липидами плазмы. На основании разработанных математических моделей было предложено использовать пороговые значения 6-сульфатоксимелатонина (метаболита мелатонина) в моче - для вечерней более 4,6\% и для ночной менее 55\% - как лабораторные маркеры десинхроноза, ассоциированные с риском развития метаболического синдрома [46].

Однако результаты немногочисленных исследований с введением экзогенного мелатонина для контроля уровня лептина остаются противоречивыми. В исследовании Gonciarz M. и соавт., в котором пациенты с ожирением и неалкогольной жировой болезнью печени в течение 28 дней получали мелатонин (5 мг утром и 5 мг вечером), наблюдалось увеличение концентрации лептина в плазме [47]. Согласно Celinski и соавт. (2009), однократная доза мелатонина (10 мг) снижала повышенные уровни лептина в плазме у пациентов с циррозом печени и повышала у контрольной группы [48]. Cagnacci и соавт. (2002) не наблюдали влияния однократного приема мелатонина (1 или 2 мг) днем на уровень лептина у женщин в постменопаузе [49]. Стоит отметить, что в проведенных исследованиях режимы приема препарата и его дозы не соответствовали физиологическому ритму секреции мелатонина у человека, поэтому интерпретация полученных результатов о влиянии терапии мелатонином на уровень лептина невозможна.
Другим адипокином, секретируемым жировой тканью, является адипонектин. В нескольких работах исследовались потенциальные взаимосвязи между адипонектином и мелатонином. Было установлено, что пинеалэктомия не изменяла уровни мРНК адипонектина в эпидидимальной жировой ткани у крыс [39]. Однако у мышей с ожирением и снижением экспрессии адипонектина в периваскулярном жире после введения мелатонина (100 мг/кг/день в питьевой воде в течение 8 нед) было продемонстрировано значительное повышение адипонектина. У контрольной группы мышей без ожирения, получавших мелатонин, подобного эффекта не наблюдалось [50]. Несколько исследований подтвердили положительное влияние лечения мелатонином на экспрессию генов адипонектина [51, 52].

Было показано, что у людей уровень адипонектина имеет положительную корреляцию с циркадианной амплитудой мелатонина. Лечение мелатонином приводит к восстановлению уровня адипонектина в плазме у пациентов с ожирением и неалкогольной жировой болезнью печени, для которых характерна гипоадипонектинемия [48]. Предполагают, что противовоспалительный эффект мелатонина может быть частично опосредован повышением уровня адипонектина.

\section{МЕЛАТОНИН И ПИЩЕВОЕ ПОВЕДЕНИЕ}

Пищевое поведение регулируется метаболическими (гипоталамус и ствол головного мозга) и гедонистическими (мезолимбические структуры) нейронными сетями головного мозга, которые взаимодействуют друг с другом, обеспечивая баланс физиологической регуляции голода и насыщения. Цикл голода/насыщения организма контролируется дугообразными ядрами (ДЯ) и центральным возвышением гипоталамуса. ДЯ имеют орексинергические (выделяющие нейропептид $Y$ и агутиподобный пептид) и анорексинергические (продуцирующие проопиомеланокортин и фактор транскрипции, регулируемый кокаином и амфетамином) клетки, которые соответственно стимулируют и ингибируют прием пищи.

Ритм приема пищи синхронизирован с циклом день/ ночь и контролируется центральными циркадианными часами. Поэтому в настоящее время (Mendoza, 2019) выделяют циркадианно-метаболически-гедонистический контур регуляции пищевого поведения.

В исследованиях на животных моделях показано, что мелатонин ингибирует орексигенные и стимулирует анорексигенные сигналы в ЦНС, что приводит к снижению потребления пищи в ответ на выделение мелатонина в ночные часы [31, 52]. Эффект реализуется посредством действия мелатонина на МТ1- и МТ2-рецепторы СХЯ, а также непосредственно на МТ2-рецепторы вентральной части ДЯ и центрального возвышения. Завершение сигнала мелатонина приводит к стимуляции орексигенных факторов и подавлению анорексигенных, вызывая голод. Так, мелатонин участвует в циркадианной организации энергетического баланса и регуляции цикла голод/насыщение.

Гипомелатонинемия приводит к увеличению аппетита и ассоциирована с компульсивным перееданием, пищевой аддикцией и синдромом ночной еды. 
Поскольку современное общество не зависит от источников дневного освещения и ориентировано на круглосуточную активность, влияние социальных факторов на количество, качество и, самое главное, время приема пищи огромно. В качестве примера можно привести задержку приема пищи, чтобы приспособиться к рабочим часам, или прием пищи ночью в случае ночной работы.

Результаты исследований показывают, что употребление большего количества калорий вечером и в ночное время может привести к увеличению общей калорийности питания и предпочтению пищи, богатой легкоусвояемыми углеводами и триптофаном. У работающих в ночные смены наблюдали превалирование в рационе фастфуда и калорийных блюд $[53,54]$.

В исследовании, включившем 98 человек с метаболическим синдромом, наблюдали снижение уровней мелатонина и серотонина и их обратную взаимосвязь со всеми типами нарушения пищевого поведения [55]. В другом исследовании $(\mathrm{n}=100)$ у пациентов с метаболическим синдромом не было показано снижения уровня мелатонина, но было сделано предположение о смещении его ночного пика [56].

\section{МЕЛАТОНИН И СОН}

Депривация сна является известной причиной метаболических нарушений, таких как ожирение, инсулинорезистентность, сахарный диабет и метаболический синдром как у детей, так и у взрослых [57]. Депривация сна приводит к задержке циркадианной фазы секреции мелатонина и повышению уровня лептина [43, 57]. Даже незначительное ежедневное укорочение ночного сна, которое может не ощущаться человеком, увеличивает резистентность к инсулину и массу тела [58].

Тесная связь между ночным повышением уровня мелатонина и наступлением сна у человека предполагает участие данного гормона в регуляции сна, которое начали изучать в 1970-х гг. Существование связи между увеличением синтеза эндогенного мелатонина в ночное время и «открытием ворот сна» подтолкнуло ученых высказать предположение о способности мелатонина индуцировать наступление сна посредством блокады механизма, поддерживающего бодрствование. Эта концепция приписывает ночной выработке мелатонина свойство переключения организма с биологического дня на биологическую ночь. В связи с этим выдвинуто предположение, что прием мелатонина может, регулируя циркадианный ритм активности/бодрствования, инициировать сон и улучшать его качество [59].

Значимость мелатонина для сна оценивалась в исследованиях пациентов, перенесших пинеалэктомию. Несмотря на некоторые противоречивые сообщения, чаще у таких лиц наблюдались нарушение циркадианного ритма, сокращение общей продолжительности сна, возрастание количества ночных пробуждений и плохое качество сна [60]. В большинстве случаев все симптомы исчезали при лечении мелатонином [60]. При этом чем ниже был исходный уровень мелатонина, тем выше была эффективность препарата. Это подтвердило гипотезу о роли мелатонина в регулировании сна и показало, что лечение мелатонином способствовало нормализации циркадианного ритма, что было подтверждено актиграфическим мониторированием.
Мелатонин может влиять на сам механизм сна: на мышах с нокаутом MT1 и МТ2 продемонстрировано, что рецептор МТ2 связан с частотой фаз сна с быстрыми движениями глаз, тогда как MT1 - с частотой фаз с медленными движениями глаз [61, 62].

Систематические обзоры и метаанализы показали эффективность мелатонина и его аналогов для лечения нарушений засыпания, увеличения общей продолжительности сна, уменьшения количества ночных пробуждений и улучшения качества сна $[63,64]$.

Прием мелатонина в дозе 3-6 мг способствует наступлению сна. Однако мелатонин выступает не столько в роли снотворного средства, сколько в качестве препарата, влияющего на временные характеристики сна.

В отечественном мультицентровом проспективном исследовании $(\mathrm{n}=2062)$ применения мелатонина в дозе 3 мг при нарушениях сна у больных дисциркуляторной энцефалопатией было выявлено положительное влияние препарата на время засыпания, число ночных пробуждений, продолжительность сна, качество сна и утреннего пробуждения [65].

\section{РАСПРОСТРАНЕННЫЕ ПРИЧИНЫ СНИЖЕНИЯ СИНТЕЗА И НАРУШЕНИЯ ДЕЙСТВИЯ МЕЛАТОНИНА}

Когда мы рассматриваем мелатонин как гормон, мы можем говорить о синдромах, характеризующихся повышением или снижением его секреции, нарушением гормональной передачи сигнала из-за дефекта рецепторов и смещением времени синтеза мелатонина.

Для диагностики этих состояний необходимо адекватно определить уровень мелатонина, причем неоднократно в течение дня. Уровень мелатонина можно оценивать в крови и слюне, а также возможно исследование 6-сульфатоксимелатонина в моче.

В отличие от любого другого измерения уровня гормонов, когда биологические образцы обычно собираются в утренние часы, образцы крови и слюны для исследования на мелатонин собирают в течение вечера и ночи при очень низком уровне освещения, избегая света синего спектра. В идеале пациент должен находиться в темной комнате или под красным светом очень низкой интенсивности (менее 30-50 люкс). И, поскольку время биологического полураспада мелатонина составляет 45 мин, собирать образцы крови необходимо каждые 30-60 мин в течение всей ночи [66]. Сбор крови не должен влиять на сон пациентов, поскольку это может привести к быстрому смещению эндогенного циркадианного ритма и неверным измерениям. Слюну обычно собирают в начале вечера.

Этих проблем можно избежать, если определять концентрации мелатонина по количеству его метаболитов в моче. Экскреция сульфатоксимелатонина с мочой пропорциональна общему количеству мелатонина, продуцируемого в данную ночь, при условии, что пациент отдыхает при низком уровне освещенности. Сбор мочи от заката до первого мочеиспускания на следующее утро является чувствительным показателем, характеризующим общий объем ночного синтеза мелатонина. Нередко проводят сбор двух порций мочи - дневной (с 11:00 до 23:00) и ночной (с 23:00 и 9:00) и сравнивают содержание в них 6-сульфатоксимелатонина. 


\section{ГИПОМЕЛАТОНИНЕМИЯ}

Гипомелатонинемия характеризуется снижением ночной пиковой величины мелатонина или общей продукции по сравнению с ожидаемой в соответствии с половозрастным показателем. Для гипомелатонинемии характерно повышение риска развития сахарного диабета 2 типа, онкологических заболеваний (главным образом - рака молочной железы и простаты).

Первичная гипомелатонинемия может развиваться вследствие:

- агенезии или гипоплазии эпифиза;

- нарушения симпатической иннервации эпифиза;

- биохимических дефектов синтеза мелатонина;

- хирургической пинеалэктомии или облучения области эпифиза.

К причинам вторичной гипомелатонинемии относятся:

- повреждение спинного мозга, приводящее к тетраплегии;

- шейно-грудная симпатэктомия;

- нейродегенеративные заболевания (болезнь Паркинсона, болезнь Хантингтона, болезнь Альцгеймера, депрессия);

- генетические заболевания, не связанные непосредственно с эмбриональным развитием эпифиза и его иннервацией (например, дефицит сепиаптеринредуктазы, приводящий к снижению синтеза серотонина и резкому снижению синтеза мелатонина без суточного ритма; фатальная семейная инсомния и синдром Морвана);

- гипергликемия при сахарном диабете;

- ожирение;

- увеличение ночной освещенности;

- прием лекарств, снижающих выработку мелатонина (например, $\beta$-блокаторов, блокаторов кальциевых каналов, ингибиторов ангиотензина);

- старение.

При старении наблюдаются типичные клинические проявления синдрома гипомелатонинемии, такие как нарушение сна и циркадианных ритмов, инсулинорезистентность и/или сахарный диабет, артериальная гипертензия, ожирение, иммунодефицит и более высокая частота онкологических процессов. Некоторые из этих симптомов могут быть устранены с помощью терапии мелатонином, что указывает на патофизиологическую роль, которую играет естественное снижение выработки мелатонина при старении.

При циркадианном сдвиге секреции мелатонина пиковый уровень гормона обычно не изменяется, но кривая содержания мелатонина в крови смещается во времени. Это может быть полное смещение на дневное время, как при синдроме Смита-Магенис, или задержка, как при синдроме дефицита внимания и гиперактивности. Также может наблюдаться полная асинхронность с циклом свет/темнота, как это наблюдается, например, у слепых людей. Симптомы, связанные с циркадианным сдвигом секреции мелатонина, включают в себя сон-бодрствование в необычное время, дневную сонливость или сон, низкую дневную работоспособность, нарушение ночного сна, хронологически неуместное пищевое поведение (синдром ночной еды) и инсулинорезистентность $[37,67,68]$. Одной из самых распростра- ненных причин хронического десинхроноза является сменная работа.

При неадекватном рецепторном ответе, несмотря на физиологическую секрецию мелатонина, из-за генетических вариаций мелатониновых рецепторов (обычно однонуклеотидных полиморфизмов) ответ органов-мишеней на мелатониновый сигнал нарушается.

Полиморфизм мелатониновых рецепторов не обязательно приводит к их полному выключению. При этом рецепторный ответ может проявляться в виде как снижения, так и повышения чувствительности. Патологии, связанные с полиморфизмом мелатониновых рецепторов, включают сахарный диабет 2 типа и гестационный диабет [37, 69].

\section{ПЕРСПЕКТИВЫ ПРИМЕНЕНИЯ МЕЛАТОНИНА ПРИ ЭКЗОГЕННО-КОНСТИТУЦИОНАЛЬНОМ ОЖИРЕНИИ}

Имеющиеся экспериментальные данные позволяют рассматривать мелатонин в качестве перспективного средства для лечения метаболического синдрома и отдельных его компонентов, в частности, экзогенно-конституционального ожирения.

Введение мелатонина крысам с ожирением приводило к снижению массы тела, уменьшению потребления пищи и увеличению содержания бурой жировой ткани [70]. У женщин в постменопаузе с избыточным весом терапия мелатонином вызывала уменьшение жировой массы и увеличение мышечной массы [71].

При этом терапевтическое действие мелатонина распространяется на разные компоненты заболевания: на нарушение секреции адипокинов жировой тканью и поджелудочной железой, пищевое поведение, циркадианный десинхроноз и нарушения сна.

Была высказана гипотеза, что возможными механизмами действия мелатонина при ожирении и сахарном диабете 2 типа являются антиоксидантное и противовоспалительное. На животных моделях показано, что мелатонин блокирует перекисное окисление в митохондриях и стимулирует синтез митофусина-2 (Mtf2) - белка, участвующего в восстановлении митохондрий после диеты с высоким содержанием жиров у мышей с ожирением [72]. Экзогенный мелатонин также уменьшает воспаление жировой ткани путем ингибирования экспрессии генов провоспалительных цитокинов NLRP3-зависимой каспазы-1 и IL-1 $\beta$.

Однако в первую очередь мелатонин реализует позитивные эффекты на метаболизм за счет своего хронобиотического действия. Поэтому при назначении мелатонина важно руководствоваться кривой фазового отклика, чтобы определить правильное время приема препарата. Именно нерациональные доза и время введения мелатонина могут быть причиной противоречивых результатов исследований в этой области.

Физиологический синтез мелатонина точно рассчитывается каждый день, и его начало помогает синхронизировать эндогенные циркадианные часы с центральным водителем ритма одновременно с запуском биологической ночи для организма. Раннее утреннее прекращение синтеза мелатонина, усиленное светом, прекращает биологическую ночь и запускает биологический день. В дополнение к этому ежедневному изменению сигнала 
мелатонина каждый организм обладает индивидуальной историей пика производства мелатонина. Т. е. профиль мелатонина является уникальным для каждого человека, с большими межиндивидуальными вариациями, но при этом для каждого человека он хорошо воспроизводится изо дня в день.

Продолжительность мелатонинового сигнала и его начало варьируют от человека к человеку, в основном в зависимости от хронотипа и индивидуального типа продолжительности сна (утренний или вечерний тип, длительный или короткий сон). «Жаворонки» (люди с утренним хронотипом) начинают синтез мелатонина раньше, чем «совы» (люди с вечерним хронотипом), и продолжительность ночного эпизода синтеза мелатонина у длительно спящих больше, чем у коротко спящих. Следует также учитывать, что одна и та же доза мелатонина может приводить к различным концентрациям мелатонина в плазме у разных пациентов из-за межиндивидуальных различий в абсорбции, распределении, метаболизме и элиминации мелатонина, которые связаны с возрастом, клиническим состоянием, заболеваниями желудочно-кишечного тракта, печени и почек. Эти факторы, если они не будут должным образом учтены, могут потенциально повлиять на желаемую клиническую эффективность применения мелатонина.

Все вышесказанное обусловливает тот факт, что терапия мелатонином эффективна только в случае индивидуально подобранной дозы и формы препарата и врачебного контроля.

Первым и наиболее важным аспектом является определение начала синтеза мелатонина у каждого пациента и назначение мелатонина в соответствии с этим моментом времени. Поскольку определение мелатонинового профиля затруднительно в повседневной клинической практике, более рациональный подход заключается в том, чтобы соотнести применение мелатонина с так называемым обычным временем засыпания. Время, которое человек выбирает для сна, определяется в большинстве случаев хронотипом (если это допускается социальными ограничениями). Поскольку большинство пероральных составов мелатонина имеют период биодоступности от 45 минут до 1 ч, желательно назначать прием мелатонина за 1 ч до обычного времени засыпания. Так как мелатонин является мощным таймером, следует строго соблюдать время приема препарата.

Вторым аспектом, который необходимо учитывать перед назначением мелатонина, является то, что его ночной фармакологический профиль должен быть ограничен естественной биологической ночью каждого пациента. Иными словами, следует разумно рассмотреть дозу и форму (быстрого, замедленного или комбинированного высвобождения) препарата.

Если речь идет о хронической терапии, как в случае с ожирением, предпочтительным является препарат, который сможет создавать концентрацию в крови, достаточно высокую, чтобы установить время циркадианных часов, а продолжительность фармакологического ночного профиля будет такой, чтобы он заканчивался к обычному времени пробуждения пациента. Это важный момент, поскольку фармакологический профиль мелатонина, в отличие от физиологического, не подвергается утреннему фотоингибированию. Дневная сонливость является критерием, который следует рассматривать как показатель избыточного расширения фармакологического профиля мелатонина. Золотым стандартом, позволяющим контролировать адекватность дозы препарата (который редко используют в повседневной практике, но к которому прибегают в исследованиях), является измерение мелатонина плазмы или слюны или 6-сульфатоксимелатонина мочи в ранние утренние часы.

Доза препарата является еще одним важным вопросом, по которому в литературе нет единого мнения. В зависимости от области клинического применения диапазон используемых дозировок варьирует от 0,1 мг/сут для одномоментной синхронизации центральных часов, от 0,6 до 5 мг/сут для лечения нарушений сна до 300 мг/сут для лечения бокового амиотрофического склероза или даже 2000 мг при кратковременном введении препарата (табл. 1) [73]. Рекомендованной дозы препарата для лечения ожирения на данный момент не существует. Мы предполагаем, что в этом случае при расчете дозы препарата можно ориентироваться на доминирующие клинические проявления (беспокоит ли пациента инсомния, подвергается ли он джет-лагам или хроническому десинхронозу).

То же самое относится к форме и способам введения (пероральный, назальный, сублингвальный, трансбуккальный, пластырь и внутривенный).

Как правило, если необходим резкий (в течение нескольких дней) сдвиг циркадианной фазы (например, при лечении джет-лага), то препарат быстрого высвобождения, принятый в правильно рассчитанное время, является средством выбора. Если желаемый терапевтический эффект заключается в длительном смещении фазы (например, при сменной работе), синхронизирующий эффект требует длительного непрерывного ежедневного применения мелатонина. Для этой цели наиболее подходящим является препарат с замедленным высвобождением. Когда желаемым результатом является компенсация уровня мелатонина, наиболее подходящим будет препарат замедленного высвобождения, который мог бы создать фармакологический профиль, наиболее приближенный к физиологическому.

Также необходимо заметить, что концентрация и профиль мелатонина в крови зависят от абсорбции, транспорта и метаболизма препарата в печени. В последнем случае необходимо учитывать взаимодействие мелатонина и других препаратов, метаболизируемых цитохромом Р450, особенно СYР1А2.

Считается, что мелатонин лишен токсических побочных эффектов и является безопасным лекарственным средством. На животных моделях летальная доза при пероральном приеме препарата или подкожном введении недостижима, нежелательные явления не были обнаружены. Несмотря на большое количество исследований клинического применения мелатонина, лишь немногие были рандомизированными двойными слепыми, в которых можно было бы проверить безопасность и неблагоприятные эффекты экзогенного мелатонина у людей [74]. Согласно результатам большого количества работ, введение мелатонина человеку безопасно и не сопровождается развитием нежелательных явлений [73].

В исследовании, включившем 238 человек с метаболическим синдромом, артериальной гипертензией 
Таблица 1. Препараты мелатонина

\begin{tabular}{|c|c|c|c|c|}
\hline Составы & Доза & $\begin{array}{c}\text { Лекарственная } \\
\text { форма }\end{array}$ & Область применения & $\begin{array}{c}\text { Торговые } \\
\text { наименования }\end{array}$ \\
\hline \multirow{14}{*}{$\begin{array}{l}\text { Немедленного } \\
\text { высвобождения }\end{array}$} & $0,125 \mathrm{Mr}$ & таблетки, капсулы & $\begin{array}{l}\text { Терапия сезонного аффективного } \\
\text { расстройства }\end{array}$ & - \\
\hline & $0,3 \mathrm{мг}$ & таблетки, капсулы & $\begin{array}{l}\text { В составе терапии никотиновой } \\
\text { зависимости }\end{array}$ & Меларена ${ }^{\circledast}$ \\
\hline & $0,5 \mathrm{Mr}$ & таблетки, капсулы & & - \\
\hline & $1 \mathrm{Mr}$ & $\begin{array}{l}\text { таблетки, капсулы, } \\
\text { мягкие гелевые } \\
\text { капсулы, порошок }\end{array}$ & Терапия джет-лага & - \\
\hline & $1 \mathrm{Mr}$ & $\begin{array}{l}\text { интраназальный } \\
\text { спрей }\end{array}$ & $\begin{array}{l}\text { Терапия инсомнии (препарат } \\
\text { находится во II фазе клинических } \\
\text { испытаний) }\end{array}$ & - \\
\hline & $1 \mathrm{Mr}$ & $\begin{array}{l}\text { сублингвальные } \\
\text { таблетки, } \\
\text { оральный спрей }\end{array}$ & $\begin{array}{l}\text { В составе терапии пародонтита, } \\
\text { мукозита, онкологических } \\
\text { заболеваний }\end{array}$ & - \\
\hline & $1,5 \mathrm{Mr}$ & таблетки & Терапия инсомнии, джет-лага & Меларитм ${ }^{\circledR}$ \\
\hline & $2 \mathrm{Mr}$ & $\begin{array}{l}\text { таблетки, капсулы, } \\
\text { масляный раствор }\end{array}$ & Терапия инсомнии, джет-лага & - \\
\hline & $3 \mathrm{Mr}$ & $\begin{array}{l}\text { таблетки, капсулы, } \\
\text { порошок }\end{array}$ & $\begin{array}{l}\text { В составе терапии эпилепсии, } \\
\text { мигрени, нарушений развития } \\
\text { нервной системы, терапия инсомнии, } \\
\text { джет-лага, нарушений циркадианного } \\
\text { ритма (в том числе у незрячих) }\end{array}$ & 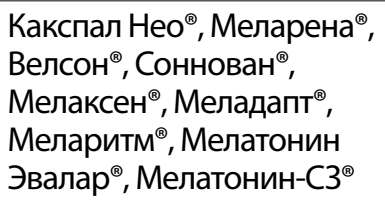 \\
\hline & $3 \mathrm{Mr}$ & $\begin{array}{l}\text { сублингвальные } \\
\text { таблетки, } \\
\text { оральный спрей }\end{array}$ & $\begin{array}{l}\text { В составе терапии пародонтита, } \\
\text { мукозита, онкологических } \\
\text { заболеваний, премедикация перед } \\
\text { хирургическими вмешательствами }\end{array}$ & - \\
\hline & $5 \mathrm{Mr}$ & таблетки & $\begin{array}{l}\text { В составе терапии эпилепсии, } \\
\text { инсомнии, синдрома хронической } \\
\text { усталости }\end{array}$ & - \\
\hline & $10 \mathrm{мг}$ & таблетки & $\begin{array}{l}\text { В составе терапии миодистрофии } \\
\text { Дюшенна, онкологических } \\
\text { заболеваний, кластерной головной } \\
\text { боли, рассеянного склероза }\end{array}$ & - \\
\hline & $50 \mathrm{мг}$ & таблетки & $\begin{array}{l}\text { В составе терапии миодистрофии } \\
\text { Дюшенна, рассеянного склероза }\end{array}$ & - \\
\hline & 5 мг/мл & $\begin{array}{l}\text { раствор } \\
\text { для инъекций } \\
\text { (в/M, в/в) }\end{array}$ & $\begin{array}{l}\text { Премедикация перед } \\
\text { хирургическими вмешательствами, } \\
\text { в составе терапии ишемии } \\
\text { головного мозга новорожденного, } \\
\text { респираторного дистресс-синдрома, } \\
\text { эпилепсии, синдрома Смита-Магенис, } \\
\text { синдрома дефицита внимания } \\
\text { и гиперактивности и других } \\
\text { неврологических заболеваний, } \\
\text { сопровождающихся первичным или } \\
\text { вторичным нарушением сна }\end{array}$ & - \\
\hline \multirow{4}{*}{$\begin{array}{l}\text { Модифицированного } \\
\text { высвобождения }\end{array}$} & $1 \mathrm{Mr}$ & таблетки & \multirow{3}{*}{$\begin{array}{l}\text { Терапия инсомнии, нарушений } \\
\text { циркадианного цикла (в том } \\
\text { числе у незрячих и работающих } \\
\text { посменно), джет-лага, сезонного } \\
\text { аффективного расстройства }\end{array}$} & - \\
\hline & $2 \mathrm{Mr}$ & таблетки & & Циркадин \\
\hline & $5 \mathrm{Mr}$ & таблетки & & - \\
\hline & $2,1 \mathrm{Mr}$ & патч & $\begin{array}{l}\text { Терапия инсомнии, нарушений } \\
\text { циркадианного цикла (препарат } \\
\text { находится на II фазе клинических } \\
\text { испытаний) }\end{array}$ & - \\
\hline
\end{tabular}


и нарушениями сна, были показаны эффективность, безопасность и удобство применения комбинации мелатонина (2 мг, таблетки с пролонгированным высвобождением) и метформина (2000 мг/сут). При оценке динамики суточного профиля артериального давления обратили на себя внимание изменения, произошедшие с таким показателем, как степень ночного снижения артериального давления ( $<<0,05$, различие между группами с приемом метформина и комбинации метформина и мелатонина), являющимся важным предиктором кардиоваскулярного риска [75].

На данный момент требуются дальнейшие контролируемые исследования для лучшего понимания терапевтической ценности мелатонина в лечении экзогенно-конституционального ожирения и сравнения эффективности разных режимов лечения мелатонином.

\section{ЗАКЛЮЧЕНИЕ}

Мелатонин является уникальным гормоном, синхронизирующим эндогенные циркадианные ритмы организма, физиологию и поведение с окружающей средой.

Активное использование искусственного освещения и электронных устройств, излучающих свет синего спектра, в том числе в ночное время, в современном урбанистическом обществе значительно влияет на секрецию мелатонина, приводя к хронической гипомелатонинемии.

Депривация сна и нарушения пищевого поведения, обусловленные гипомелатонинемией, наряду с гиподинамией, могут вносить существенный вклад в распространение «неинфекционной эпидемии XXI в.» - экзогенно-конституционального ожирения.

Применение препаратов мелатонина у лиц с экзогенно-конституциональным ожирением и особенно имеющих дополнительные причины для развития гипомелатонинемии (например, работающих посменно, подвергающихся освещению в ночные часы и т. д.), оказывает положительное действие на показатели метаболического здоровья. Можно предположить, что применение мелатонина при ожирении будет эффективно даже в отсутствие циркадианного десинхроноза за счет антиоксидантного и противовоспалительного действия мелатонина.

Для подтверждения этой гипотезы требуются дальнейшие проспективные контролируемые рандомизированные исследования. При их планировании важно учитывать правила назначения препаратов мелатонина (доз и времени их приема у человека), чтобы избежать ошибок, допущенных в проводимых ранее исследованиях.

\section{ДОПОЛНИТЕЛЬНАЯ ИНФОРМАЦИЯ}

Источник финансирования. Работа выполнена по инициативе авторов без привлечения финансирования.

Конфликт интересов. Авторы декларируют отсутствие явных и потенциальных конфликтов интересов, связанных с публикацией настоящей статьи.

Информация о вкладе каждого автора. Цветкова Е.С. - разработка концепции, составление плана рукописи, анализ публикаций, сбор и систематизация данных; Романцова Т.И. - редактирование рукописи, внесение важных правок; Полуэктов М.Г. - редактирование рукописи, внесение важных правок; Рунова Г.Е. - редактирование рукописи, внесение важных правок; Глинкина И.В. - редактирование рукописи, внесение важных правок. Все авторы одобрили финальную версию статьи перед публикацией, выразили согласие нести ответственность за все аспекты работы, подразумевающую надлежащее изучение и решение вопросов, связанных с точностью или добросовестностью любой части работы.

\section{СПИСОК ЛИТЕРАТУРЫ | REFERENCES}

1. Benedito-Silva A, Evans S, Viana Mendes J, et al. Association between light exposure and metabolic syndrome in a rural Brazilian town. PLoS One. 2020;15(9):e0238772. doi: https://doi.org/10.1371/journal.pone.0238772

2. Rahman S, St Hilaire M, Gronfier C, et al. Functional decoupling of melatonin suppression and circadian phase resetting in humans. J Physiol. 2018;596(11):2147-2157. doi: https://doi.org/10.1113/jp275501.

3. Gooley JJ, Chamberlain K, Smith KA, et al. Exposure to Room Light before Bedtime Suppresses Melatonin Onset and Shortens Melatonin Duration in Humans. Endocrinology. 2011;152(2):742-742. doi: https://doi.org/10.1210/endo.152.2.zee742

4. Acuna-Castroviejo D, Escames G, Venegas C, et al. Extrapineal melatonin: sources, regulation, and potential functions. Cell Mol Life Sci. 2014;71(16):2997-3025. doi: https://doi.org/10.1007/s00018-014-1579-2

5. Xia Y, Chen S, Zeng S, et al. Ren Melatonin in macrophage biology: Current understanding and future perspectives. J Pineal Res. 2019;66(2):e12547. doi: https://doi.org/10.1111/jpi.12547.

6. Olcese JM. Melatonin and Female Reproduction: An Expanding Universe. Front. Endocrinol. 2020;1 1:85. doi:10.3389/fendo.2020.00085.

7. Reiter R, Sharma R, Rosales-Corral S. Anti-Warburg Effect of Melatonin: A Proposed Mechanism to Explain its Inhibition of Multiple Diseases. Int J Mol Sci. 2021;22(2):764. doi: https://doi.org/10.3390/ijms22020764

8. Konturek SJ, Konturek PC, Brzozowska I, et al. Localization and biological activities of melatonin in intact and diseased gastrointestinal tract (GIT). J Physiol Pharmacol. 2007 Sep;58(3):381-405
9. Majidinia M, Sadeghpour A, Mehrzadi S, et al. Melatonin A pleiotropic molecule that modulates DNA damage response and repair pathways. J Pineal Res. 2017;63(1) doi: https://doi.org/10.1111/jpi.12416.

10. Boutin JA. Quinone Reductase 2 as a Promising Target of Melatonin Therapeutic Actions. Expert Opin. Ther. Targets. 2016;20:303-317. doi: https://doi.org/10.1517/14728222.2016.1091882

11. Wang X, Sirianni A, Pei Z, et al. The Melatonin MT1 Receptor Axis Modulates Mutant Huntingtin-mediated Toxicity. J. Neurosci. 2011;31:14496-15507. doi: https://doi.org/10.1523/JNEUROSCI.3059-11.2011.

12. Vriend J, Reiter RJ. Melatonin feedback on clock genes: a theory involving the proteasome. J Pineal Res. 2015;58(1):1-11. doi: https://doi.org/10.1111/jpi.12189.

13. Stauch B, Johansson L, Cherezov V. Structural insights into melatonin receptors. FEBS J. 2019;287(8):1496-1510. doi: https://doi.org/10.1111/febs.15128.

14. Jockers R, Delagrange P, Dubocovich ML, et al. Update on melatonin receptors: IUPHAR Review 20. Br J Pharmacol. 2016;173(18):2702-2725. doi: https://doi.org/10.1111/bph.13536

15. Brydon L, Petit L, Delagrange $P$, et al. Functional expression of MT2 (Mel1b) melatonin receptors in human PAZ6 adipocytes. Endocrinology. 2001;142(10):4264-4271. doi: https://doi.org/10.1210/endo.142.10.8423.

16. Zibolka J, Bazwinsky-Wutschke I, Mühlbauer E, Peschke E. Distribution and density of melatonin receptors in human main pancreatic islet cell types. J Pineal Res. 2018;65(1):e12480. doi: https://doi.org/10.1111/jpi.12480. 
17. Tan D, Manchester L, Terron M, et al. Melatonin as a naturally occurring co-substrate of quinone reductase-2, the putative MT3melatonin membrane receptor: hypothesis and significance. J Pineal Res. 2007:43(4):317-320. doi: https://doi.org/10.1111/j.1600-079x.2007.00513.x

18. Pariente R, Bejarano I, Espino J, et al. Participation of MT3 melatonin receptors in the synergistic effect of melatonin on cytotoxic and apoptotic actions evoked by chemotherapeutics. Cancer Chemother Pharmacol. 2017;80(5):985-998. doi: https://doi.org/10.1007/s00280-017-3441-3

19. Boutin J, Ferry G. Is There Sufficient Evidence that the Melatonin Binding SiteMT3Is Quinone Reductase 2? Journal of Pharmacology and Experimental Therapeutics. 2019;368(1):59-65. doi: https://doi.org/10.1124/jpet.118.253260

20. Smirnov AN. Nuclear melatonin receptors. Biochemistry (Mosc). 2001;66(1):19-26. doi: https://doi.org/10.1023/a:1002821427018

21. Owino S, Sánchez-Bretaño A, Tchio C, et al. Nocturnal activation of melatonin receptor type 1 signaling modulates diurnal insulin sensitivity via regulation of PI3K activity. J Pineal Res. 2018;64(3). doi: https://doi.org/10.1111/jpi.12462

22. Costes S, Boss M, Thomas AP, Matveyenko AV. Activation of Melatonin Signaling Promotes $\beta$-Cell Survival and Function. Mol Endocrinol. 2015;29(5):682-692. doi: https://doi.org/10.1210/me.2014-1293

23. Kemp DM, Ubeda M, Habener JF. Identification and functional characterization of melatonin Mel 1a receptors in pancreatic beta cells: potential role in incretin-mediated cell function by sensitization of CAMP signaling. Mol Cell Endocrinol. 2002;191(2):157-166. doi: https://doi.org/10.1016/S0303-7207(02)00064-3

24. Arendt J, Broadway J. Light and melatonin as zeitgebers in man. Chronobiol Int. 1987;4(2):273-282. doi: https://doi.org/10.3109/07420528709078534

25. Pagano ES, Spinedi E, Gagliardino JJ. White Adipose Tissue and Circadian Rhythm Dysfunctions in Obesity: Pathogenesis and Available Therapies. Neuroendocrinology. 2017;104(4):347-363. doi: https://doi.org/10.1159/000453317

26. Pfeffer M, Korf H-W, Wicht H. Synchronizing effects of melatonin on diurnal and circadian rhythms. Gen Comp Endocrinol. 2018;258:215-221. doi: https://doi.org/10.1016/j.ygcen.2017.05.013

27. Nogueira TC, Lellis-Santos C, Jesus DS, et al. Absence of melatonin induces night-time hepatic insulin resistance and increased gluconeogenesis due to stimulation of nocturnal unfolded protein response. Endocrinology. 2011;152(4):1253-1263. doi: https://doi.org/10.1210/en.2010-1088

28. Ferreira DS, Amaral FG, Mesquita CC, et al. Maternal melatonin programs the daily pattern of energy metabolism in adult offspring. PloS one. 2012;7(6):e38795. doi: https://doi.org/10.1371/journal.pone.0038795

29. Rubio-Sastre P, Scheer FA, Gomez-Abellan P, et al. Acute melatonin administration in humans impairs glucose tolerance in both the morning and evening. Sleep (Basel). 2014;37(10):1715-1719. doi: https://doi.org/10.5665/sleep.4088

30. Buonfiglio D, Parthimos R, Dantas R, et al. Melatonin Absence Leads to Long-Term Leptin Resistance and Overweight in Rats. Front Endocrinol. 2018;9:122. doi: https://doi.org/10.3389/fendo.2018.00122.

31. Anhe GF, Caperuto LC, Pereira-Da-Silva M, et al. In vivo activation of insulin receptor tyrosine kinase by melatonin in the rat hypothalamus. J Neurochem. 2004;90(3):559-566. doi: https://doi.org/10.1111/j.1471-4159.2004.02514.x

32. Mulder H, Nagorny CLF, Lyssenko V, Groop L. Melatonin receptors in pancreatic islets: good morning to a novel type 2 diabetes gene. Diabetologia. 2009;52(7):1240-1249. doi: https://doi.org/10.1007/s00125-009-1359-y.

33. Reinehr $\mathrm{T}$, Scherag $\mathrm{A}$, Wang $\mathrm{H}-\mathrm{J}$, et al. Relationship between MTNR1B (melatonin receptor $1 \mathrm{~B}$ gene) polymorphism rs10830963 and glucose levels in overweight children and adolescentst. Pediatr Diabetes. 2011;12(4pt2):435-441 doi: https://doi.org/10.1111/j.1399-5448.2010.00738.x

34. McMullan CJ, Curhan GC, Schernhammer ES, Forman JP. Association of nocturnal melatonin secretion with insulin resistance in nondiabetic young women. Am J Epidemiol. 2013;178(2):231-238. doi: https://doi.org/10.1093/aje/kws470

35. McMullan CJ, Schernhammer ES, Rimm EB, et al. Melatonin secretion and the incidence of type 2 diabetes. JAMA. 2013;309(13):1388-1396. doi: https://doi.org/10.1001/jama.2013.2710.
36. Gil-Lozano M, Hunter PM, Behan L-A et al. Short-term sleep deprivation with nocturnal light exposure alters time-dependent glucagon-like peptide-1 and insulin secretion in male volunteers. Am J Physiol Endocrinol Metab. 2016;310(1):E41-E50. doi: https://doi.org/10.1152/ajpendo.00298.2015

37. Tarnowski M, Malinowski D, Safranow K, et al. MTNR1A and MTNR1B gene polymorphisms in women with gestational diabetes. Gynecol Endocrinol : Off J Int Soc Gynecol Endocrinol. 2017;33(5):395-398. doi: https://doi.org/10.1080/09513590.2016.1276556

38. Leitner C, Bartness TJ. An intact dorsomedial hypothalamic nucleus, but not the subzona incerta or reuniens nucleus, is necessary for short-day melatonin signal-induced responses in Siberian hamsters. Neuroendocrinology. 2011;93(1):29-39. doi: https://doi.org/10.1159/000320474

39. de Farias T da SM, de Oliveira AC, Andreotti S, et al. Pinealectomy interferes with the circadian clock genes expression in white adipose tissue. J Pineal Res. 2015;58(3):251-261. doi: https://doi.org/10.1111/jpi.12211

40. Jiménez-Aranda A, Fernández-Vázquez G, Campos D, et al. Melatonin induces browning of inguinal white adipose tissue in Zucker diabetic fatty rats. J Pineal Res. 2013;55(4):416-423. doi: https://doi.org/10.1111/jpi.12089

41. Halpern B, Mancini MC, Bueno C, et al. Melatonin Increases Brown Adipose Tissue Volume and Activity in Patients With Melatonin Deficiency: A Proof-of-Concept Study. Diabetes. 2019;68(5):947-952. doi: https://doi.org/10.2337/db18-0956

42. de Souza CAP, Gallo CC, de Camargo LS, et al. Melatonin multiple effects on brown adipose tissue molecular machinery. J Pineal Res. 2019:66(2):e12549. doi: https://doi.org/10.1111/jpi.12549

43. Nduhirabandi F, du Toit EF, Lochner A. Melatonin and the metabolic syndrome: a tool for effective therapy in obesityassociated abnormalities? Acta Physiol. 2012;205(2):209-223. doi: https://doi.org/10.1111/j.1748-1716.2012.02410.x

44. Corbalán-Tutau D, Madrid JA, Nicolás F, Garaulet M. Daily profile in two circadian markers "melatonin and cortisol" and associations with metabolic syndrome components. Physiol \& Behav. 2014;123:231-235. doi: https://doi.org/10.1016/j.physbeh.2012.06.005.

45. Mäntele S, Otway DT, Middleton B, et al. Daily rhythms of plasma melatonin, but not plasma leptin or leptin mRNA, vary between lean, obese and type 2 diabetic men. PloS one. 2012;7(5):e37123. doi: https://doi.org/10.1371/journal.pone.0037123.

46. Бобко О.В., Тихомирова О.В., Зыбина Н.Н., Клиценко О.А. Маркеры десинхроноза в оценке риска развития метаболического синдрома // Медичинский алфавит. - 2019. - Т. 1. — №4. C. 21-26. [Bobko OV, Tikhomirova OV, Zybina NN, Klitsenko OA. Desynchronosis markers in risk assessment of metabolic syndrome development. Med Alph. 2019;1(4):21-26 (in Russ.)]. doi: https://doi.org/10.33667/2078-5631-2019-1-4(379)-21-26

47. Gonciarz M, Bielański W, Partyka R, et al. Plasma insulin, leptin, adiponectin, resistin, ghrelin, and melatonin in nonalcoholic steatohepatitis patients treated with melatonin. J Pineal Res. 2013;54(2):154-161. doi: https://doi.org/10.1111/j.1600-079X.2012.01023.X

48. Celinski K, Konturek PC, Slomka M, et al. Altered basal and postprandial plasma melatonin, gastrin, ghrelin, leptin and insulin in patients with liver cirrhosis and portal hypertension without and with oral administration of melatonin or tryptophan. J Pineal Res. 2009:46(4):408-414. doi: https://doi.org/10.1111/j.1600-079X.2009.00677.x.

49. Cagnacci A, Malmusi S, Zanni A, et al. Acute modifications in the levels of daytime melatonin do not influence leptin in postmenopausal women. J Pineal Res. 2002;33(1):57-60. doi: https://doi.org/10.1034/j.1600-079X.2002.01893.X

50. Agabiti-Rosei C, De Ciuceis C, Rossini C, et al. Anticontractile activity of perivascular fat in obese mice and the effect of longterm treatment with melatonin. J Hypertens. 2014;32(6):1264-1274. doi: https://doi.org/10.1097/HJH.0000000000000178

51. Nduhirabandi F, Huisamen B, Strijdom H, et al. Short-term melatonin consumption protects the heart of obese rats independent of body weight change and visceral adiposity. J Pineal Res. 2014;57(3):317-332. doi: https://doi.org/10.1111/jpi.12171

52. Montalbano G, Mania M, Abbate F, et al. Melatonin treatment suppresses appetite genes and improves adipose tissue plasticity in diet-induced obese zebrafish. Endocrine. 2018;62(2):381-393. doi: https://doi.org/10.1007/s12020-018-1653-x 
53. McHill AW, Phillips AJ, Czeisler CA, et al. Later circadian timing of food intake is associated with increased body fat. Am J Clin Nutr. 2017;106(5):1213-1219. doi: https://doi.org/10.3945/ajcn.117.161588.

54. Movahed MR, Lee JZ, Lim WY, et al. Strong independent association between obesity and essential hypertension. Clin Obes 2016;6(3):189-192. doi: https://doi.org/10.1111/cob.12139.

55. Алексеева Н.С., Салмина-Хвостова О.И., Белобородова Е.В. Взаимосвязь нарушений пищевого поведения с уровнем мелатонина и серотонина при метаболическом синдроме // Сибирский вестник психиатрии и наркологии. - 2016. T. 4. - №93. - C. 39-44. [Alekseeva NS, Salmina-Khvostova OI, Beloborodova EV. Interrelationship of eating disorders and level of melatonin and serotonin in metabolic syndrome. Sibirskii vestnik psikhiatrii i narkologii. 2016:4(93):39-44 (in Russ.)]

56. Успенский Ю.П., Соусова Я.В., Фоминых Ю.А. Оценка роли гормонов в формировании пищевого поведения у пациентов с метаболическим синдромом // Дневник Казанской медицинской школы. - 2019. - Т. 2. — №24. - C. 8-14. [Uspenskii YuP, Sousova YaV, Fominykh YuA. An evaluation of the role of hormones in the formation of food behavior in patients with metabolic syndrome. Dnevnik Kazanskoi meditsinskoi shkoly. 2019;2(24):8-14 (in Russ.)].

57. Reiter RJ, Tan D-X, Korkmaz A, Ma S. Obesity and metabolic syndrome: association with chronodisruption, sleep deprivation, and melatonin suppression. Ann Med. 2012;44(6):564-577. doi: https://doi.org/10.3109/07853890.2011.586365

58. Arora T, Chen MZ, Cooper AR, et al. The Impact of Sleep Debt on Excess Adiposity and Insulin Sensitivity in Patients with Early Type 2 Diabetes Mellitus. J Clin sleep Med JCSM : Off Publ Am Acad Sleep Med. 2016;12(5):673-680. doi: https://doi.org/10.5664/jcsm.5792

59. Quera-Salva MA, Claustrat B. Melatonin: Physiological and pharmacological aspects related to sleep:

The interest of a prolonged-release formulation (Circadin ${ }^{\oplus)}$ in insomnia. Encephale. 2018;44(6):548-557. doi: https://doi.org/10.1016/j.encep.2018.06.005

60. Májovský M, Řezáčová L, Sumová A, et al. Melatonin and cortisol secretion profile in patients with pineal cyst before and after pineal cyst resection. J Clin Neurosci: Off J Neurosurg Soc Australas. 2017;39:155-163. doi: https://doi.org/10.1016/j.jocn.2017.01.022.

61. Comai S, Ochoa-Sanchez R, Gobbi G. P.1.g.109 Distinct role of melatonin MT1 and MT2 receptors in sleep and anxiety: insights from melatonin receptor knockout mice. Eur Neuropsychopharmacol 2014;24:S268. doi: https://doi.org/10.1016/S0924-977X(14)70420-1

62. Ochoa-Sanchez R, Comai S, Lacoste B, et al. Promotion of non-rapid eye movement sleep and activation of reticular thalamic neurons by a novel MT2 melatonin receptor ligand. J Neurosci: Off J Soc Neurosci. 2011;31(50):18439-18452. doi: https://doi.org/10.1523/JNEUROSCI.2676-11.2011

63. Auld F, Maschauer EL, Morrison I, et al. Evidence for the efficacy of melatonin in the treatment of primary adult sleep disorders. Sleep Med Rev. 2017;34:10-22. doi: https://doi.org/10.1016/j.smrv.2016.06.005.

64. Ferracioli-Oda E, Qawasmi A, Bloch MH. Meta-Analysis: Melatonin for the Treatment of Primary Sleep Disorders. Focus (Madison). 2014;12(1):73-79. doi: https://doi.org/10.1176/appi.focus.12.1.73
65. Полуэктов М.Г., Левин Я.И., Бойко А.Н., и др. Результаты российского мультицентрового исследования эффективности и безопасности мелаксена (мелатонин) для лечения нарушений сна у пациентов с хронической церебральной сосудистой недостаточностью // Журнал неврологии и психиатрии им. С.С. Корсакова. - 2012. - Т. 112. - №9. - C. 26-31. [Poluektov MG, Levin Yal, Boiko AN. The results of Russian multicenter open-label observational study of the efficacy and safety of melaxen (melatonin) for the treatment of disordered sleep in patients with chronic cerebral ischemia. Zhurnal nevrologii i psikhiatrii im. SS Korsakova. 2012;112(9):26-31. (in Russ.)].

66. Lewy AJ, Ahmed S, Jackson JM, Sack RL. Melatonin shifts human circadian rhythms according to a phase-response curve. Chronobiol Int. 1992;9(5):380-392. doi: https://doi.org/10.3109/07420529209064550

67. Eckel RH, Depner CM, Perreault L, et al. Morning Circadian Misalignment during Short Sleep Duration Impacts Insulin Sensitivity. Curr Biol :CB. 2015;25(22):3004-3010. doi: https://doi.org/10.1016/j.cub.2015.10.011

68. Barboni MTS, Bueno C, Nagy BV, et al. Melanopsin System Dysfunction in Smith-Magenis Syndrome Patients. Investig Ophthalmol \& Vis Sci. 2018;59(1):362-369. doi: https://doi.org/10.1167/iovs.17-22612

69. Bonnefond A, Froguel P. The case for too little melatonin signalling in increased diabetes risk. Diabetologia. 2017;60(5):823-825. doi: https://doi.org/10.1007/s00125-017-4255-x

70. Zanuto R, Siqueira-Filho MA, Caperuto LC, et al. Melatonin improves insulin sensitivity independently of weight loss in old obese rats. J Pineal Res. 2013;55(2):156-165. doi: https://doi.org/10.1111/jpi.12056

71. Amstrup AK, Sikjaer T, Pedersen SB, et al. Reduced fat mass and increased lean mass in response to 1 year of melatonin treatment in postmenopausal women: A randomized placebo-controlled trial. Clin Endocrinol. 2016;84(3):342-347. doi: https://doi.org/10.1111/cen.12942

72. Reiter RJ, Rosales-Corral S, Tan DX, et al. Melatonin as a mitochondriatargeted antioxidant: one of evolution's best ideas. Cell Mol life Sci: CMLS. 2017;74(21):3863-3881. doi: https://doi.org/10.1007/s00018-017-2609-7

73. Sanchez-Barcelo EJ, Mediavilla MD, Tan DX, Reiter RJ. Clinical Uses of Melatonin: Evaluation of Human Trials. Curr Med Chem. 2010;17(19):2070-2095. doi: https://doi.org/10.2174/092986710791233689

74. Seabra ML, Bignotto M, Pinto LR, Tufik S. Randomized, doubleblind clinical trial, controlled with placebo, of the toxicology of chronic melatonin treatment. J Pineal Res. 2000;29(4):193-200. doi: https://doi.org/10.1034/j.1600-0633.2002.290401.x

75. Недогода С.В., Смирнова В.О., Барыкина И.Н., и др. Влияние терапии препаратом мелатонина на функцию эндотелия, артериальное давление и сосудистую жесткость у пациентов с метаболическим синдромом и нарушениями сна // Артериальная гипертензия. - 2017. - Т. 23. - №2. C. 150-159. [Nedogoda SV, Smirnova VO, Barykina IN, et al. Effects of melatonin on blood pressure, endothelial function and vascular stiffness in patients with metabolic syndrome and sleep disorders. Arterial Hypertens. 2017;23(2):150-159. (in Russ.)]. doi: https://doi. org/10.18705/1607-419X-2017-23-2-150-159

ИНФОРМАЦИЯ ОБ АВТОРАХ [AUTHORS INFO]:

*Цветкова Евдокия Сергеевна [Evdokiia S. Tsvetkova, MD]; адрес: Россия, 119991, ул. Б. Пироговская, д. 2, стр. 4 [address: 2-4 Bolshaya Pirogovskaya st., 119991 Moscow, Russia]; ORCID: https://orcid.org/0000-0002-5421-0981; eLibrary SPIN: 9047-4183; e-mail: evatsvetkova.md@gmail.com

Романцова Татьяна Ивановна, д.м.н., профессор [Tatiana I. Romantsova, MD, PhD, professor]; ORCID: https://orcid.org/0000-0003-3870-6394; eLibrary SPIN: 3855-5410; e-mail: romantsovatatiana@rambler.ru Полуэктов Михаил Гурьевич, к.м.H. [Mikhail G. Poluektov, MD, PhD]; ORCID: https://orcid.org/0000-0001-6215-0918; eLibrary SPIN: 7539-9525; e-mail: polouekt@mail.ru

Рунова Гюзель Евгеньевна, к.M.H. [Guzel E. Runova, MD, PhD]; ORCID: https://orcid.org/0000-0003-2144-8595; eLibrary SPIN: 3639-6932; e-mail: guzelvolkova@yandex.ru

Глинкина Ирина Владимировна, к.M.н. [Irina V. Glinkina, MD, PhD]; ORCID: https://orcid.org/0000-0001-8505-5526; eLibrary SPIN: 2731-2400; e-mail: irina_glinkina@rambler.ru

Фадеев Валентин Викторович, д.м.Н., профессор [Valentin V. Fadeev, MD, PhD, professor]; ORCID: https://orcid.org/0000-0002-3026-6315; eLibrary SPIN: 6825-8417; e-mail: walfad@mail.ru

*Автор, ответственный за переписку / Corresponding author. 


\section{ЦИТИРОВАТЬ:}

Цветкова Е.С., Романцова Т.И., Полуэктов М.Г., Рунова Г.Е., Глинкина И.В., Фадеев В.В. Значение мелатонина в регуляции метаболизма, пищевого поведения, сна и перспективы его применения при экзогенно-конституциональном ожирении // Ожирение и метаболизм. — 2021. — Т. 18. — №2. — C. 112-124. doi: https://doi.org/10.14341/omet12279

\section{TO CITE THIS ARTICLE:}

Tsvetkova ES, Romantsova TI, Poluektov MG, Runova GE, Glinkina IV, Fadeev VV. The importance of melatonin in the regulation of metabolism, eating behavior, sleep, and the prospects for the use of melatonin drugs for obesity treatment. Obesity and metabolism. 2021;18(2):112-124. doi: https://doi.org/10.14341/omet12279 